\title{
Usability of one-class classification in mapping and detecting changes in bare peat surfaces in the tundra
}

\section{Räsänen, Aleksi}

2019-01

Räsänen , A , Elsakov , V \& Virtanen , T 2019 , ' Usability of one-class classification in mapping and detecting changes in bare peat surfaces in the tundra ', International Journal of Remote Sensing , vol. 40 , no. 11 , pp. 4083-4103 . https://doi.org/10.1080/01431161.2018.1558376

http://hdl.handle.net/10138/301621

https://doi.org/10.1080/01431161.2018.1558376

acceptedVersion

Downloaded from Helda, University of Helsinki institutional repository.

This is an electronic reprint of the original article.

This reprint may differ from the original in pagination and typographic detail.

Please cite the original version. 


\section{Usability of one-class classification in mapping and detecting changes \\ 2 in bare peat surfaces in the tundra}

3 Aleksi Räsänen, corresponding author

4 Ecosystems and Environment Research Programme, Faculty of Biological and

5 Environmental Sciences, and Helsinki Institute of Sustainability Science (HELSUS),

6 PO Box 65, FI-00014 University of Helsinki, Finland, aleksi.rasanen@helsinki.fi

7 Department of Geography, Norwegian University of Science and Technology, NO-7491

8 Trondheim, Norway

9 Vladimir Elsakov

10 Institute of Biology of Komi Scientific Centre of the Ural Branch of the Russian

11 Academy of Sciences, Kommunisticheskaya, 28, Syktyvkar, Komi Republic, Russia,

12 elsakov@ib.komisc.ru

13 Tarmo Virtanen

14 Ecosystems and Environment Research Programme, Faculty of Biological and

15 Environmental Sciences, and Helsinki Institute of Sustainability Science (HELSUS),

16 PO Box 65, FI-00014 University of Helsinki, Finland, tarmo.virtanen@ helsinki.fi

17 word count: 10,357

18

19

20

21

22 


\section{Usability of one-class classification in mapping and detecting changes 25 in bare peat surfaces in the tundra}

Arctic areas have experienced greening and changes in permafrost caused by climate change during recent decades. However, there has been a lack of automated methods in mapping changes in fine-scale patterns of permafrost landscapes. We mapped areal coverage of bare peat areas and changes in them in a peat plateau located in north-western Russia between 2007 and 2015. We utilized QuickBird and WorldView-3 satellite image data in an object-based setting. We compared four different one-class classifiers (one-class support vector machine, binary support vector machine, random forest, rotation forest) both in a fully supervised binary setting and with positive and unlabelled training data. There was notable variation in classification performance. The bare peat area $F$-score varied between 0.77 and 0.96 when evaluated by cross-validated training data and between 0.22 and 0.57 when evaluated by independent test data. Overall, random forest performed the most robustly but all classifiers performed well in some classifications. During the 8 year period, there was a $21 \%-26 \%$ decrease in the bare peat areal coverage. We conclude that (1) tested classifiers can be used in one-class settings and (2) there is a need to develop methods for tracking changes in single land cover types.

Keywords: Arctic, change detection, land cover, one-class classification, remote sensing, very high spatial resolution

\section{Introduction}

Arctic areas in general and Arctic peatlands in particular have been heavily influenced by recent global warming. It has been reported that the Arctic is greening, usually meaning that the amount of green vegetation, especially bush coverage, is increasing in tundra areas (Tape, Sturm and Racine 2006; Elmendorf et al. 2012; Myers-Smith et al. 2015; Yu et al. 2017), and that climate warming and geomorphic disturbances have caused changes in permafrost areas (Beck et al. 2015; Segal, Lantz and Kokelj 2016; Borge et al. 2017; Obu et al. 2017). It has been found that bare peat surfaces, the identification of which is the target of our study, can be significant nitrous oxide, carbon 
54 dioxide and methane sources in the tundra (Repo et al. 2009; Marushchak et al. 2011;

55 Voigt et al. 2016). Furthermore, their areal coverage seems to be dynamic in time and their abundance in the Arctic is still poorly known (Repo et al. 2009; Marushchak et al. 2011; Voigt et al. 2016).

Remote sensing methods are widely used in mapping Arctic land cover and permafrost (Pflugmacher et al. 2011; Westermann et al. 2014; Bartsch et al. 2016) and tracking changes in land cover patterns (Singh 1989; Stow et al. 2004; Beck et al. 2015; Tewkesbury et al. 2015; Jorgenson and Grosse 2016). Due to fine-scale heterogeneity in thermokarst and tundra environments, very high spatial resolution (VHSR, spatial resolution $<5.00 \mathrm{~m}$ ) satellite images are needed to map the extent and spatial patterns of small land cover patches such as bare peat surfaces (Laidler and Treitz 2003; Belshe, Schuur and Grosse 2013; Virtanen and Ek 2014). It has been argued that more highresolution studies are needed to map changes in Arctic environments, and there is a need to develop standardized methods for tracking the changes (Jorgenson and Grosse 2016).

There are some but not many previous studies evaluating fine-scale changes in permafrost landscapes. Borge et al. (2017) combined visual interpretation with an analysis of climate data when they evaluated the decrease in palsa mires in northern Norway. Similarly, visual interpretation has been used in the mapping of changes in thermokarst lakes and lithalsas in Quebec (Beck et al. 2015) and in thaw slump activity

74 in the western Canadian Arctic (Segal et al. 2016). While these studies have incorporated visual interpretation, there has been a lack of automated approaches for mapping changes in fine-scale patterns of single land cover classes. To map patches of single land cover classes, there has been a recent rise in the use of one-class, binary and positive and unlabelled (PU) classification methods as 
opposed to multi-class classification methods (Boyd, Sanchez-Hernandez and Foody

80 2006; Sanchez-Hernandez, Boyd and Foody 2007; Li and Guo 2010; Li, Guo and Elkan 2011; Mack, Roscher and Waske 2014; Baldeck and Asner 2015; Baldeck et al. 2015;

Barbosa et al. 2016; Chen et al. 2016; Mack et al. 2016; Song et al. 2016; Mack and

Waske 2017; Stenzel et al. 2017; Araya-López et al. 2018; Deng et al. 2018; Liu et al. 2018). In one-class classification, training data are needed only for the focal class (i.e. presence data). This makes it easier to use than multi-class classification in which training data are needed for all classes. In PU classifications, there are also training data for unlabelled (so-called pseudo-outlier) points, whereas binary classifiers are performed in a one-against-all setting. Typical methods in one-class, PU and binary classification include support vector machines (SVMs) (Boyd et al. 2006; Sanchez-Hernandez et al. 2007; Baldeck and Asner 2015; Mack et al. 2016; Stenzel et al. 2017), a maximum entropy approach (Maxent) (Li and Guo 2010; Lin et al. 2014; Stenzel et al. 2014; Amici et al. 2017; Andrew and Shephard 2017; Stenzel et al. 2017; Chignell et al. 2018; Noviello et al. 2018), as well as PU and presence and background learning algorithms (Li et al. 2011; Xu et al. 2016; Ao et al. 2017; Deng et al. 2018; Liu et al. 2018). Also, regression methods such as random forest (RF) and boosted regression trees have been used in mapping the presence of single land cover types (Chignell et al. 2018), while state-ofthe-art classification methods other than SVMs, Maxent and PU learning have been 99 little used.

100 SVM is a non-parametric statistical learning technique in which observations are 101 divided into classes with the help of hyperplanes (Vapnik 1982; Mountrakis, Im and 102 Ogole 2011). In one-class SVM (OCSVM), only positive data are used in the training of 103 the classifier; in biased SVM, PU data are used, and positive data are given a larger 
104 misclassification cost; and in binary SVM, data from two classes are used (Baldeck and

105 Asner 2015; Baldeck et al. 2015; Barbosa et al. 2016; Mack et al. 2016; Mack and

106 Waske 2017; Stenzel et al. 2017). Maxent is a one-class machine learning method in

107 which relative entropy between two probability densities (i.e. presence data and

108 environmental covariates) is trying to be minimized (Elith et al. 2011). Maxent has been

109 typically used in the modelling of suitable habitats or species distributions of specific

110 species using remote sensing and other data (Phillips, Anderson and Schapire 2006;

111 Elith et al. 2011), but it has also been used in other kinds of remote sensing tasks, such

112 as mapping archaeological sites (Noviello et al. 2018), eagle nests (Andrew and

113 Shephard 2017) and habitat types (Stenzel et al. 2014; Chignell et al. 2018). As the

114 name of the method indicates, the PU learning algorithm uses PU data in model

115 building. The PU learning algorithm is carried out in two steps: the model is first trained

116 with PU data, and a specific constant factor is estimated from validation data (Li et al.

117 2011). PU learning needs to be implemented with a classification algorithm that can

118 estimate conditional probabilities. Usually, PU has been implemented with back-

119 propagation neural networks (Li et al. 2011; Xu et al. 2016; Ao et al. 2017; Deng et al.

120 2018) but also model comparisons have been conducted (Liu et al. 2018).

121 When comparing different classification algorithms, it has been found that

122 biased and binary SVMs in particular are promising methods for mapping patches of

123 rare habitat type (Boyd et al. 2006; Sanchez-Hernandez et al. 2007; Mack et al. 2016;

124 Stenzel et al. 2017) and that they usually outperform other one-class classification

125 methods (Boyd et al. 2006; Baldeck and Asner 2015; Baldeck et al. 2015; Barbosa et al.

126 2016; Mack and Waske 2017; Stenzel et al. 2017). In some comparisons against biased

127 or binary SVMs, slightly higher classification accuracy has been achieved with iterative 
128 biased SVM (Mack et al. 2016) and the PU learning algorithm (Li et al. 2011; Xu et al.

129 2016; Ao et al. 2017; Deng et al. 2018; Liu et al. 2018).

130 Here, we address three gaps in the remote sensing literature. First, we assess

131 one-class classification in tracking fine-scale changes in tundra environments, which

132 have been studied relatively little. Second, there have been few attempts to use one-

133 class and PU classification methods to track changes, and these studies have employed

134 Maxent (Lin et al. 2014; Amici et al. 2017) or OCSVM (Li and Xu 2010) in rather

135 coarse resolution mapping. Here, we map fine-scale changes in bare peat surfaces in

136 Russian tundra using VHSR satellite images at two time points (2007 and 2015). Third,

137 although there has been a notable increase in one-class, biased and binary

138 classifications, there has been little evaluation of how methods other than SVM, Maxent

139 and PU learning handle the binary and PU classification situations. Hence, we test the

140 performance of RF and rotation forest (ROF) against binary/biased SVM (BSVM) and

141 OCSVM. We evaluate these methods in an object-based setting by comparing fully

142 supervised binary classification (i.e. peat surfaces against all other land cover classes)

143 with PU classification in which we used training data from bare peat areas and

144 unlabelled random points.

\section{Materials and methods}

\subsection{Study area and bare peat surfaces}

147 Our study area is in the Seida peat plateau $\left(67^{\circ} 04^{\prime} 00^{\prime \prime} \mathrm{N}, 62^{\circ} 55^{\prime} 00^{\prime \prime} \mathrm{E}\right.$, Figure 1$)$ located

148 in a discontinuous permafrost zone in the Usa River Basin in the north-eastern corner of

149 European Russia, $70 \mathrm{~km}$ south-west of the town of Vorkuta. The area is characterized

150 by low Arctic shrub vegetation and lies just north of the tree line. The mean annual

151 temperature in the region is approximately $-6{ }^{\circ} \mathrm{C}$ and the annual precipitation is just 
152 above $505 \mathrm{~mm}$ (Repo et al. 2009; Marushchak et al. 2011; Hugelius et al. 2012; Voigt et

153 al. 2016). The area is composed of a mosaic of peat plateaus, mineral moraine deposits,

154 and thermokarst lakes. Peat plateaus with permafrost bogs and fens rise above the

155 surrounding landscape due to high ground ice content, and the peat layer is in many

156 locations over $4 \mathrm{~m}$ thick (Hugelius et al. 2012).

$157 \quad$ FIGURE 1 APPROXIMATELY HERE

158 We tracked the areal coverage and changes in the extent of bare peat surfaces,

159 whose coverage has been estimated to be around 1\% of the peat plateau (Marushchak et

160 al. 2013). These surfaces have been developed by late Holocene permafrost aggradation

161 (Väliranta et al. 2018), wind erosion (Seppälä 2003) and soil mixing due to frost action,

162 i.e. cryoturbation (Bockheim and Tarnocai 1998; Peterson and Krantz 2003; Repo et al.

163 2009). According to recent findings, the surfaces are remnants of larger non-vegetated

164 areas in the past (Väliranta et al. 2018). Bare peat surfaces are of two types. Peat circles

165 are flat surfaces with no vascular plants but are partly covered by thin moss and algal

166 crust. Peat mounds are drier than peat circles and partly vegetated by lichens and

167 graminoids. Peat mounds do not have a frozen core but are located within a frozen peat

168 plateau (Marushchak et al. 2011).

\subsection{Used data}

170 In the classifications, we used two VHSR satellite images taken during different

171 growing seasons. The first one was a QuickBird (QB) image (DigitalGlobe,

172 Westminster, CO, USA) with $2.40 \mathrm{~m}$ spatial resolution and four bands (blue, green, red,

173 near-infrared) taken on 6 July 2007. The second one was a WorldView-3 (WV-3) image

174 (DigitalGlobe, Westminster, CO, USA) with $1.60 \mathrm{~m}$ spatial resolution and eight bands

175 (coastal blue, yellow, red-edge and near-infrared 2 in addition to the QB bands) taken on 9 August 2015. We first atmospherically corrected both images using the dark-object 
177 subtraction method (Chavez 1988) and then georeferenced them to match the field data and each other.

179 To acquire the ground reference data, we used (1) visual interpretation of

180 satellite images and (2) a DJI (Dà-Jiāng Innovations) Phantom 2 Vision Plus drone

181 image with 0.04 m resolution taken on 2 August 2015 as well as (3) fieldwork data sets

182 from July-August 2007 and 2016. The mosaic of drone images (nearly 615 images) was

183 developed using Agisoft PhotoScan software (Agisoft, St Petersburg, Russia). In the

184 fieldwork, we collected data mostly for a purpose other than mapping bare peat areas

185 but got a good overall view of the bare peat areas and received help in how they could

186 be interpreted from satellite images.

\subsection{Overview of the classification approach}

188 It has been shown that object-based methods are more applicable than pixel-based

189 methods in classifying VHSR images (Blaschke et al. 2014). Therefore, we employed

190 an object-based classification approach in which we first segmented images and then

191 classified them in two different settings (Figure 2). In the first classification setting, we

192 carried out a fully supervised binary classification and in the second setting, we

193 classified the image with the help of PU segments (PU classification setting). In both

194 settings, we tested four different classifiers and reduced the number of features using a

195 feature selection algorithm. Finally, we assessed classification accuracy in a different

196 area than the training area. Classifications were carried out separately for the QB and

197 WV-3 images. For WV-3, we carried out two classification alternatives: a low-

198 resolution (we use the acronym WV-3LR) version with data resampled at $2.40 \mathrm{~m}$

199 ground resolution and four bands identical to QB classification, and a high-resolution

200 (WV-3HR) version with $1.60 \mathrm{~m}$ resolution and all eight bands. 
203 We segmented images using full lambda schedule (FLS) segmentation in Erdas Imagine

2042014 (Intergraph, Madison, AL, USA). FLS segmentation is a region-based

205 segmentation in which pixels are merged with their neighbouring pixels if certain

206 conditions are met. FLS uses spectral (mean pixel value in the segment), textural

207 (standard deviation of pixel values in the segment), shape (areal complexity of the

208 segment) and size information when decisions about merging are carried out. This

209 information can be given relative weights. Furthermore, the average size of the segment

210 (i.e. pixel/segment ratio) and the minimum and maximum segment sizes can also be

211 adjusted.

212 We parameterized segmentations with the help of visual interpretation as it is

213 often the most meaningful method for segmentation evaluation in natural environments

214 (Räsänen et al. 2013). When setting the parameters, we had three objectives: (1) the

215 segments should be as large as possible, but (2) even the smaller bare peat areas should

216 be delineated, and (3) the average size of the segment should be the same for all

217 classifications. We ended up giving weights of $0.7,0.5,0.3$ and 0.3 to spectral, textural,

218 shape and size information respectively. Hence, we gave the largest relative weight to

219 spectral information as the bare peat surfaces usually have a distinct colour in the

220 images. We set the pixel/segment ratio to 50 for $2.40 \mathrm{~m}$ resolution classifications and to

221112 for the $1.60 \mathrm{~m}$ resolution classification, and we gave minimum and maximum

222 segment sizes the default values of 10 and 2000 respectively.

\subsection{Calculated features}

224 For each segment and image band, we calculated 34 features using package EBImage

225 (Pau et al. 2010) in R 3.2.2 (R Core Team 2015). To analyse texture, we calculated the 
following 13 grey-level co-occurrence matrix (GLCM) features: angular second moment, contrast, correlation, sum of squares: variance, inverse difference moment, sum average, sum variance, sum entropy, entropy, difference variance, difference entropy, and two information measures of correlation (Haralick, Dinstein and Shanmugam 1973) which are among the most widely used textural features (Benz et al. 2004; Pacifici, Chini and Emery 2009; Blaschke et al. 2014). When calculating the

232 GLCM features, we quantized data to 32 levels. We calculated all GLCM features at two scales; in other words, we calculated the adjacency of pixels to their closest and second closest neighbouring pixels. In addition, we calculated mean, standard deviation, mean absolute deviation, and 1\%, 5\%, 50\%, 95\% and 99\% quantiles. We calculated

236 features from each image band as well as from three band indices: normalized

237 difference vegetation index (NDVI, Rouse et al. 1973), red-green index (RGI, Coops et al. 2006) and normalized difference water index (McFeeters 1996). Hence, we ended up with 374 features for the WV-3HR classification and 238 features for the QB and WV3LR classifications.

\subsection{Classification settings}

242 We used two classification settings: binary and PU. For the binary classification, we

243 manually classified an area of the images for bare peat segments and other segments.

244 We carried out this classification in the area where most of the fieldwork in 2016 was

245 conducted. We used our knowledge of the terrain collected during the fieldwork and 246 visual interpretation of the VHSR images when constructing the training data. In binary 247 classifications, we ended up with 122 (WV-3HR), 92 (WV-3LR) and 98 (QB) segments 248 for the bare peat class, and 1112 (WV-3HR), 1027 (WV-3LR) and 1067 (QB) for the 249 other class (Figure 3). For the PU classification, we used the same bare peat areas as for 250 the binary classification. For the unlabelled points, we randomly drew 1000 segments 
from the overall study area.

\section{FIGURE 3 APPROXIMATELY HERE}

\subsection{Used classifiers and their parameterization}

We used four different classifiers: OCSVM, BSVM, ROF and RF in both classification settings.

SVMs have been used widely in binary, PU and one-class settings, and BSVM has performed the best in various comparisons (Baldeck and Asner 2015; Baldeck et al. 2015; Barbosa et al. 2016; Mack and Waske 2017; Stenzel et al. 2017). In SVMs, observations are divided into a discrete number of classes with the help of hyperplanes, and the closest training samples to the hyperplanes are called support vectors (Vapnik 1982; Mountrakis et al. 2011). In its simplest form, SVM is a linear binary classifier. However, there are also techniques such as kernels that modify hyperplanes so that separability between classes does not need to be linear and also further adjustments that enable classification into multiple classes (Mountrakis et al. 2011). SVM generally needs only small training data sets and handles multidimensional data sets making it appealing for remote sensing classification tasks (Mountrakis et al. 2011). We used a radial basis function kernel (Vert, Tsuda and Schölkopf 2004) when conducting SVM classifications in one-class, biased and binary settings. SVMs are sensitive to changes in parameter values and typically a grid search is used in parameterization (Mack et al. 2014; Baldeck and Asner 2015; Baldeck et al. 2015; Barbosa et al. 2016; Mack et al. 2016; Mack and Waske 2017; Stenzel et al. 2017).

OCSVM uses only data from the positive class and searches for the optimal configuration that separates the positive class (Schölkopf et al. 2000). In OCSVM with radial basis function kernel, two parameters need to be set: inverse kernel width $(\sigma)$ (Vert et al. 2004) and the upper bound for the training error (v) (Schölkopf et al. 2000). 
276 After initial evaluation we tested the following parameter values: $\sigma \in\left\{1 \times 10^{-7}, 1 \times 10^{-6}\right.$,

$\left.277 \ldots, 1 \times 10^{-2}\right\}$ and the upper bound for the training error $v \in(0.01,0.05,0.10, \ldots, 0.25\}$.

278 Binary and biased SVM use data from two classes in training. In binary SVM, it

279 is known that training samples originate from two different classes. The classifier tries

280 to maximize the distance between the hyperplane and support vector and minimize

281 misclassifications. Misclassifications are penalized using a cost parameter $(C)$ (Vapnik

282 1982). In biased SVM, unlabelled samples may include samples from the positive class

283 (Liu et al. 2003). Therefore, two classes are given a different weight through $C$;

284 misclassifications of the focal class are penalized more than misclassifications in the

285 unlabelled samples using an extra cost parameter $C+$ (Liu et al. 2003). We tested the

286 following parameter values with BSVM: $\sigma \in\left\{1 \times 10^{-7}, 1 \times 10^{-6}, \ldots, 1 \times 10^{-2}\right\}, C \in\{1 \times$

$\left.28710^{3}, 1 \times 10^{4}, \ldots, 1 \times 10^{7}\right\}$ and $C+\in\left\{1 \times 10^{0}, 1 \times 10^{1}, \ldots, 1 \times 10^{5}\right\}$. We thus allowed

288 equal misclassification costs for both classes. For both OCSVM and BSVM, we tuned

289 parameters using tenfold cross-validation.

290 RF has generally performed well in various comparisons and it is capable of

291 handling multidimensional data (Duro, Franklin and Dubé 2012; Rodriguez-Galiano et

292 al. 2012; Adam et al. 2014; Belgiu and Dragut 2016). It is an ensemble classifier which

293 combines multiple bootstrapped classification trees, and final classification is based on

294 a majority vote over all trees. When a tree is built, two thirds of the data are used for

295 training and the rest is used for evaluation and is called out-of-bag data. At each tree

296 node, the best split is chosen among a randomized subset of input features and the

297 number of tested features can be adjusted (Breiman 2001). In order to deal with

298 imbalanced data, one can increase the misclassification cost of a specific class by giving

299 a higher value to the class weight ( $W$ ) parameter (Chen, Liaw and Breiman 2004). We

300 tuned $W$ using out-of-bag assessment. After initial testing to find a suitable range for the 
301 positive class $W$, we tested the following values: $W \in\left\{1 \times 10^{5}, 2 \times 10^{5}, \ldots, 19 \times 10^{5}\right\}$.

302 Otherwise, RF has been found to be insensitive to parameterization (Rodriguez-Galiano 303 et al. 2012; Du et al. 2015), which we also verified in our initial evaluations. Thus, we

304 used the default values for the other parameters. We set the number of trees grown to

305500 and the number of parameters tested in each node to the square root of the total 306 number of variables.

307 ROF has proven to be an efficient method for classifying remote sensing data

308 (Kavzoglu and Colkesen 2013) and it has outperformed SVM and RF in some

309 comparisons (Du et al. 2015). ROF is also an ensemble classifier of multiple

310 classification trees. In each tree, features are randomly split into subsets, and principal

311 component analysis is conducted for each subset so that the full feature set can be

312 reconstructed with subset axis rotation. Confidence for each class is calculated using an

313 average combination over all trees, and samples are assigned to the class with the

314 highest confidence (Rodriguez and Kuncheva 2006). Similarly to RF, ROF is insensitive

315 to parameterization (Du et al. 2015), and we verified this when testing the classifier. We

316 thus used default parameter values; in more detail, we chose the number of variable

317 subsets so that there were three features in each subset, and we set the number of trees 318 to ten.

319 For SVMs and RF, we chose the best parameter values based on the $F$-score,

320 which has been found to be applicable in binary and one-class classification settings

321 (Baldeck and Asner 2015; Baldeck et al. 2015). We conducted classifications in R 3.2.2

322 (R Core Team 2015) using packages oneClass (Mack et al. 2014), randomForest (Liaw

323 and Wiener 2002) and rotationForest (Ballings and Van der Poel 2015). 
325 In previous studies, it has been found that feature selection improves the classification 326 accuracy in SVM and RF classifications (Low et al. 2013; Rasanen et al. 2014; Li, XJ et 327 al. 2016). For selecting features, we used the RF wrapper algorithm Boruta (Kursa and 328 Rudnicki 2010) in R 3.2.2 (R Core Team 2015). Boruta and other RF-based feature 329 selection are compatible with SVMs (Low et al. 2013; Li, XJ et al. 2016) and have

330 performed well in different comparisons (Samsudin et al. 2015; Li, Tran and Siwabessy 331 2016; Poona et al. 2016). Boruta feature selection proceeds as follows. Before each RF 332 run, shadows for each feature are created. Shadow feature values are obtained by 333 disarranging the values of the original feature across samples. After the run, the features 334 which have significantly lower importance than the shadow feature with the highest 335 importance are judged to be unimportant, and features having significantly higher 336 importance are judged important. Unimportant features are removed from the following 337 runs and Boruta ends when all features are deemed either important or unimportant or 338 when the maximum amount of RF runs have been conducted (Kursa and Rudnicki 339 2010), which in our case was after 1000 runs. For those variables which were still

340 tentative after 1000 runs, we carried out a tentative rough fix in which the median

341 importance of tentative features was compared with the median importance of the most 342 important shadow feature (Kursa and Rudnicki 2010).

\subsection{Accuracy assessment and change detection}

344 We tested the accuracy of the classifications in an area covered by the drone image. In 345 constructing the reference against which classifications were evaluated, we visually

346 interpreted the drone image and delineated all bare peat areas with $>20 \mathrm{~m}^{2}$ extent. In

347 addition, we visually estimated whether the bare peat areas visible in the drone image 
348 could be seen in the satellite images. We evaluated the performance of the methods by

349 both pixel-based and object-based metrics. First, we calculated the user's accuracy (i.e.

350 precision, the likelihood that the mapped area is a bare peat surface) and the producer's

351 accuracy (i.e. recall, the proportion of correctly classified bare peat surfaces). We also

352 calculated the $F$-score (i.e. the harmonic mean of the user's and producer's accuracy)

353 based on (1) the test data and (2) the out-of-bag (RF) or tenfold cross-validated (other

354 classifiers) estimate on the training data. Furthermore, we calculated the proportion of

355 positively classified segments having at least $10 \%$ and $50 \%$ bare peat coverage based on

356 the reference data. Then, we calculated the proportion of bare peat patches in the

357 reference of which $10 \%$ or $50 \%$ were classified as bare peat surfaces in the remote

358 sensing classifications. Finally, we calculated the number and areal coverage of bare

359 peat surfaces in the validation area based on each classifier and the reference, and in the

360 whole $10.9 \mathrm{~km}^{2}$ study area of which approximately $5.5 \mathrm{~km}^{2}$ is peat plateau (see

361 Hugelius et al. 2012 for the peat plateau area).

362 To track changes in bare peat areal coverage, we compared QB and WV-3LR

363 classifications, since they had similar spectral and spatial resolutions. We compared the

364 areal coverage and number of bare peat area patches in the whole study area using the

365 following metrics. First, we calculated the consensus of 3, 5 and 7 classifiers; in other

366 words, we mapped those segments that were classified as bare peat based on the

367 prediction of 3, 5 or 7 classifiers. Second, we calculated the average values of areal

368 coverage and number of patches over all classifications and reported also the lowest and

369 highest estimate of single classifiers. 


\subsection{Feature and parameter selection}

372 The Boruta feature selection reduced the number of features to $88,80,66,54,78$ and 81

373 for the binary and PU QB, binary and PU WV-3LR, and binary and PU WV-3HR

374 classifications respectively. Features deemed important consisted usually of GLCM sum

375 average, GLCM sum variance, and mean and quantile features. Furthermore, features

376 calculated from the NDVI, RGI and the near-infrared band in the QB and WV-3LR

377 classifications, and features calculated from the red-edge band, NDVI and RGI followed

378 by red, green, and near-infrared 1 bands in the WV-3HR classifications were over-

379 represented in the final set of features. Nevertheless, some features from all bands were

380 included and all types of features were included in the final classifications.

381 In OCSVM classifications, the optimal value for $\sigma$ varied between $1 \times 10^{-4}$ and 1

$382 \times 10^{-3}$ and for $v$ between 0.01 and 0.15 . In BSVM classifications, the optimal value for $\sigma$

383 varied between $1 \times 10^{-7}$ and $1 \times 10^{-3}$, for $C$ between $1 \times 10^{3}$ and $1 \times 10^{5}$, and for $C+$

384 between $1 \times 10^{0}$ and $1 \times 10^{5}$, but in most of the classifications, $C+$ was $1 \times 10^{0}$. In all

385 BSVM classifications, $F$-scores close to the best $F$-score were obtained with several

386 parameter combinations including higher values for $C+$. In RF classifications, the

387 optimal $W$ varied between $1 \times 10^{5}$ and $10 \times 10^{5}$.

\subsection{Classification and change detection}

389 When looking at the cross-validation or out-of-bag performance of the training data, $F$ -

390 scores for the different classifications varied between 0.77 and 0.96 , with the highest $F$ -

391 scores for ROF and lowest for OCSVM (Table 1). However, the $F$-scores were notably

392 smaller (0.22-0.57) when independent test data were used (Table 1). In the six

393 comparisons based on test data, RF had the highest $F$-score in five cases. The 
394 classification accuracies were the highest for WV-3HR classifications and the lowest for

395 WV-3LR classifications, while the situation was the opposite in the evaluation based on cross-validated training data.

There was considerable variation in the classifier performance based on independent test data. All classifiers performed well in some classifications but not as

400 well in some other classifications (Tables 2-4). User accuracies varied between 22\% and $64 \%$ and producer accuracies between $22 \%$ and 60\%. OCSVM had high producer accuracies and low user accuracies especially in QB classifications and suffered thus from over-classification in some cases. BSVM was more prone to under-classification but it performed well especially in the PU WV-3 classifications. RF performed the most robustly of the classifiers but had some under-prediction problems in the WV-3LR classifications. ROF performed quite poorly in the WV-3LR classifications and underpredicted in some classifications but had also high classification accuracies in other classifications. In visual interpretation, the performance of the classifiers varied, and all classifiers produced visually acceptable classifications (Figure 4).

\section{TABLE 2 APPROXIMATELY HERE}

TABLE 3 APPROXIMATELY HERE

\section{TABLE 4 APPROXIMATELY HERE}

According to the consensus of five classifiers and average estimates, the number

415 of bare peat areas as well as their areal coverage decreased by $21 \%-26 \%$ between 2007 416 and 2015 (Table 5). Nevertheless, there was some under-prediction in many of the WV-

417 3LR classifications (Table 3). WV-3HR gave a similar area estimate and higher patch 418 number estimate than WV-3LR of on average 5.3 ha (4.5 ha -7.8 ha) in 554 patches 
419 (319-951), which could be judged as a better estimate due to higher classification accuracy. Overall, the areal coverage of bare peat was around $0.5 \%$ of the study area and $1.0 \%$ of the peat plateau.

\section{TABLE 5 APPROXIMATELY HERE}

\section{Discussion}

424 According to our results, there was considerable variation in classifier performance.

425 Although the $F$-scores were high when evaluated using cross-validated training data, 426 they were low when using independent test data. Actually, the cross-validated $F$-scores

427 were similar to the $F$-scores or accuracies received in some other studies using one-class 428 or binary classifications in relatively simple classification tasks in urban or agricultural areas (Mack et al. 2014; Ao et al. 2017; Deng et al. 2018). On the other hand, the classifier performance based on independent test data was comparable to earlier classifier performance in more challenging classification tasks in natural environments (Baldeck and Asner 2015; Stenzel et al. 2017), although higher classification accuracies

433 have also been obtained in natural environments (Baldeck et al. 2015; Mack et al. 2016). The reason for the high disparity between the classification accuracies can be related to the fact that training data and test data were derived from different areas.

436 Although the distance between the areas is only $1 \mathrm{~km}-2 \mathrm{~km}$, the composition of land 437 cover classes is to some extent different. Another possibility would have been to use 438 part of the data from both areas for training and part of the data for testing. However, in that case, we could not have used the drone image and manually delineated bare peat

440 areas in the test data, and we could only have used object-based metrics when

441 evaluating classifier performance. We judge the classifier performance based on the test 442 data as a more reliable estimate, because independent test data are usually 443 recommended (Mack and Waske 2017; Liu et al. 2018). Later in this section, we mostly 
discuss the classifier performance against the independent test data.

When evaluated using the independent test data, RF performed most robustly in

446 classifying bare peat areas, and its performance was often slightly better than OCSVM

447 or BSVM. Quite surprisingly, the performance of OCSVM was approximately on par

448 with BSVM when evaluated using independent test data, which is in contrast to

449 previous research (Li et al. 2011; Baldeck and Asner 2015; Baldeck et al. 2015; Barbosa

450 et al. 2016; Ao et al. 2017; Mack and Waske 2017; Stenzel et al. 2017; Deng et al.

451 2018). However, the performance of OCSVM was lower compared with other

452 classifiers when evaluated by the cross-validated training data. It is also notable that

453 OCSVM produced different classification results in binary and PU settings, although it

454 uses only positive data for training. These dissimilarities were probably caused by

455 different final parameter sets.

456 In previous research, there has been mixed evidence as to whether there are

457 differences in classifier performance when comparing binary and PU settings. In one

458 comparison, higher classification accuracy has been achieved with binary SVM

459 compared with biased SVM (Mack et al. 2016); in a second comparison, the situation

460 was the opposite (Baldeck et al. 2015); and in a third comparison, the difference was

461 small between the two classifiers (Baldeck and Asner 2015). According to our results,

462 there was no clear trend in classifier performance between binary and PU settings.

463 Although there were divergences in single classifiers, equally high classification

464 accuracies could be achieved in both settings. Overall, we judge that all tested

465 classifiers can be used both in binary and PU settings, and especially RF showed

466 promising performance. Therefore, the use of the PU classification setting for all tested

467 classifiers can be recommended for future studies as this setting requires training data

468 only for the positive class. 
470 decrease in bare peat areas during the last decade. Based on all comparisons, the areal

471 coverage and number of bare peat surfaces is decreasing in the area. The detected

472 decrease can be related many factors which include an actual decrease in the number

473 and size of patches, a decrease in the number of patches that could be clearly identified

474 (i.e. segmented and classified), uncertainties in classifications such as under-prediction

475 in WV-3LR classifications, and goodness of the training data. Actually, already in

476 training data of the WV-3 classifications, the areal coverage of bare peat was $16 \%$ lower

477 than in the training data of the QB classification. Overall, the decrease is supported by

478 our field observations. We have observed that vegetation density and area covered by

479 vegetation seem to be at least to some extent increased around bare peat surfaces, and

480 there seem to be no new bare peat areas. The decrease is also supported by the recent

481 evidence that current bare peat areas are remnants of larger zones of barren land

482 (Väliranta et al. 2018) and by the observations that Arctic areas are greening (Tape et al.

483 2006; Elmendorf et al. 2012; Myers-Smith et al. 2015; Yu et al. 2017). On the other

484 hand, there has been little change in thermokarst lake coverage near the study site

485 between the mid-1970s and mid-2000s (Sannel and Kuhry 2011), which might mean

486 that there has been little change in the landscape dynamics also in our study area. It

487 might also be possible that bare areas would at some time also increase, at least

488 temporarily, if a warming climate creates quick disturbances to vegetation due to

489 changes in permafrost conditions in the area.

490 In earlier research, change detection in permafrost environments has been

491 concentrated on coarse-scale patterns, while fine-scale changes have been mostly

492 tracked with visual interpretation (Jorgenson and Grosse 2016). Nevertheless, as visual

493 interpretation is labour demanding, we urge for the development of an efficient and 
automatic change tracking method for VHSR images. Furthermore, images could be

495 fused with repeat lidar analysis, which has been successfully used in tracking changes

496 (Jorgenson and Grosse 2016). Another possible avenue could be testing the resolution

497 requirements in tracking changes; in other words, what kind of changes that can be

498 detected using different resolution data sets could be assessed. In addition to

499 methodological developments, more validation studies with thorough field assessments

500 are needed to track fine-scale changes in permafrost environments.

There is a one-month difference in the timing of the QB and WV-3 images;

502

therefore, phenology might affect the classification of bare peat areas. Although there are no phenological changes in non-vegetated surfaces such as bare peat, phenology

504 affects the interpretation of other land cover classes and vegetation types (Anderson et

505 al. 2016; Wang et al. 2016; Juutinen et al. 2017). This might then have a minor

506 influence on the classification of bare peat.

507 Our results show that the higher spectral and spatial resolution of WV-3HR

508 classifications gave higher classification accuracies than QB or WV-3LR

509 classifications. Also in earlier studies, it was found that WV-3 performs better than QB

510 in various environments (Novack et al. 2011; McCarthy and Halls 2014). Overall, WV-

511 3HR classifications were the most reliable in our case and showed that high spectral and

512 spatial resolution is needed in the mapping of bare peat areas.

\section{5. Conclusion}

514 To sum up, both binary and PU classification methods were shown to be appropriate in

515 mapping bare peat surfaces, but there were significant differences in classifier

516 predictions of bare peat areas. RF was the most robust classifier in the comparison, but

517 differences between classifiers were generally small. More research is needed in

518 evaluating the performance of RF and ROF in various one-class tasks and also in 
evaluating whether single classes are better mapped in one-class than multi-class

settings. The performance of one-class methods in tracking changes was mixed and

more research should be carried out in the development of automated change detection

methods for specific single habitat types. Finally, applying one-class methods in

mapping the extent, distribution and dynamics of single habitat and land cover types at a

fine scale over a large spatial extent is a promising research avenue as low-cost VHSR

satellite images are becoming more widely available.

Acknowledgements: This research was supported by the Academy of Finland (projects 291736 and 296423).

\section{References}

Adam, Elhadi, Onisimo Mutanga, John Odindi, and Elfatih M Abdel-Rahman. 2014. RapidEye imagery: evaluating the performance of random forest and support vector machines classifiers." International journal of remote sensing 35 (10):3440-58.

Amici, V., M. Marcantonio, N. La Porta, and D. Rocchini. 2017. "A multi-temporal approach in MaxEnt modelling: A new frontier for land use/land cover change detection." Ecological Informatics 40:40-9. doi: 10.1016/j.ecoinf.2017.04.005.

Anderson, H. B., L. Nilsen, H. Tommervik, S. R. Karlsen, S. Nagai, and E. J. Cooper. 2016. "Using ordinary digital cameras in place of near-infrared sensors to derive vegetation indices for phenology studies of high arctic vegetation." Remote Sensing 8 (10). doi: 10.3390/rs8100847.

Andrew, M. E., and J. M. Shephard. 2017. "Semi-automated detection of eagle nests: an application of very high-resolution image data and advanced image analyses to wildlife surveys." Remote Sensing in Ecology and Conservation 3 (2):66-80. doi: 10.1002/rse2.38.

Ao, Z., Y. Su, W. Li, Q. Guo, and J. Zhang. 2017. "One-class classification of airborne LiDAR data in urban areas using a presence and background learning algorithm." Remote Sensing 9 (10). doi: 10.3390/rs9101001.

Araya-López, R. A., J. Lopatin, F. E. Fassnacht, and H. J. Hernández. 2018. "Monitoring Andean high altitude wetlands in central Chile with seasonal optical data: A comparison between Worldview-2 and Sentinel-2 imagery." ISPRS Journal of Photogrammetry and Remote Sensing. doi: 10.1016/j.isprsjprs.2018.04.001.

Baldeck, C. A., and G. P. Asner. 2015. "Single-Species Detection With Airborne Imaging Spectroscopy Data: A Comparison of Support Vector Techniques." Ieee Journal of Selected Topics in Applied Earth Observations and Remote Sensing 8 (6):2501-12. doi: 10.1109/jstars.2014.2346475.

Baldeck, C. A., G. P. Asner, R. E. Martin, C. B. Anderson, D. E. Knapp, J. R. Kellner, and S. J. Wright. 2015. "Operational Tree Species Mapping in a Diverse 
Tropical Forest with Airborne Imaging Spectroscopy." Plos One 10 (7). doi: 10.1371/journal.pone.0118403.

Ballings, M., and D. Van der Poel. 2015. "rotationForest: Fit and Deploy Rotation Forest Models." http://CRAN.R-project.org/package=rotationForest.

Barbosa, J. M., G. P. Asner, R. E. Martin, C. A. Baldeck, F. Hughes, and T. Johnson. 2016. "Determining Subcanopy Psidium cattleianum Invasion in Hawaiian Forests Using Imaging Spectroscopy." Remote Sensing 8 (1). doi: 10.3390/rs8010033.

Bartsch, A., A. Hofler, C. Kroisleitner, and A. M. Trofaier. 2016. "Land Cover Mapping in Northern High Latitude Permafrost Regions with Satellite Data: Achievements and Remaining Challenges." Remote Sensing 8 (12). doi: 10.3390/rs8120979.

Beck, I., R. Ludwig, M. Bernier, E. Lévesque, and J. Boike. 2015. "Assessing Permafrost Degradation and Land Cover Changes (1986-2009) using Remote Sensing Data over Umiujaq, Sub-Arctic Québec." Permafrost and Periglacial Processes 26 (2):129-41. doi: 10.1002/ppp.1839.

Belgiu, M., and L. Dragut. 2016. "Random forest in remote sensing: A review of applications and future directions." ISPRS Journal of Photogrammetry and Remote Sensing 114:24-31. doi: 10.1016/j.isprsjprs.2016.01.011.

Belshe, E. F., E. A. G. Schuur, and G. Grosse. 2013. "Quantification of upland thermokarst features with high resolution remote sensing." Environmental Research Letters 8 (3). doi: 10.1088/1748-9326/8/3/035016.

Benz, U. C., P. Hofmann, G. Willhauck, I. Lingenfelder, and M. Heynen. 2004. "Multiresolution, object-oriented fuzzy analysis of remote sensing data for GIS-ready information." ISPRS Journal of Photogrammetry and Remote Sensing 58 (34):239-58. doi: 10.1016/j.isprsjprs.2003.10.002.

Blaschke, Thomas, Geoffrey J Hay, Maggi Kelly, Stefan Lang, Peter Hofmann, Elisabeth Addink, Raul Queiroz Feitosa, Freek van der Meer, Harald van der Werff, and Frieke van Coillie. 2014. "Geographic object-based image analysistowards a new paradigm." ISPRS Journal of Photogrammetry and Remote Sensing 87:180-91.

Bockheim, J. G., and C. Tarnocai. 1998. "Recognition of cryoturbation for classifying permafrost-affected soils." Geoderma 81 (3-4):281-93. doi: 10.1016/s00167061(97)00115-8.

Borge, A. F., S. Westermann, I. Solheim, and B. Etzelmuller. 2017. "Strong degradation of palsas and peat plateaus in northern Norway during the last 60 years." Cryosphere 11 (1):1-16. doi: 10.5194/tc-11-1-2017.

Boyd, D. S., C. Sanchez-Hernandez, and G. M. Foody. 2006. "Mapping a specific class for priority habitats monitoring from satellite sensor data." International journal of remote sensing 27 (13):2631-44. doi: 10.1080/01431160600554348.

Breiman, L. 2001. "Random forests." Machine Learning 45 (1):5-32. doi: 10.1023/a:1010933404324.

Chavez, P. S. 1988. "An improved dark-object subtraction technique for atmospheric scattering correction of multispectral data." Remote Sensing of Environment 24 (3):459-79. doi: 10.1016/0034-4257(88)90019-3.

Chen, C., A. Liaw, and L. Breiman. 2004. "Using Random Forest to Learn Imbalanced Data." In Statistics Technical Reports. Berkeley, CA, USA: University of California Berkeley. 
Chen, X. H., D. M. Yin, J. Chen, and X. Cao. 2016. "Effect of training strategy for positive and unlabelled learning classification: test on Landsat imagery." Remote Sensing Letters 7 (11):1063-72. doi: 10.1080/2150704x.2016.1217437.

Chignell, S. M., M. W. Luizza, S. Skach, N. E. Young, and P. H. Evangelista. 2018. "An integrative modeling approach to mapping wetlands and riparian areas in a heterogeneous Rocky Mountain watershed." Remote Sensing in Ecology and Conservation 4 (2):150-65. doi: 10.1002/rse2.63.

Coops, N. C., M. Johnson, M. A. Wulder, and J. C. White. 2006. "Assessment of QuickBird high spatial resolution imagery to detect red attack damage due to mountain pine beetle infestation." Remote Sensing of Environment 103 (1):6780. doi: 10.1016/j.rse.2006.03.012.

Deng, X., W. Li, X. Liu, Q. Guo, and S. Newsam. 2018. "One-class remote sensing classification: One-class vs. Binary classifiers." International journal of remote sensing 39 (6):1890-910. doi: 10.1080/01431161.2017.1416697.

Du, P. J., A. Samat, B. Waske, S. C. Liu, and Z. H. Li. 2015. "Random Forest and Rotation Forest for fully polarized SAR image classification using polarimetric and spatial features." ISPRS Journal of Photogrammetry and Remote Sensing 105:38-53. doi: 10.1016/j.isprsjprs.2015.03.002.

Duro, Dennis C, Steven E Franklin, and Monique G Dubé. 2012. "A comparison of pixel-based and object-based image analysis with selected machine learning algorithms for the classification of agricultural landscapes using SPOT-5 HRG imagery." Remote Sensing of Environment 118:259-72.

Elith, J., S. J. Phillips, T. Hastie, M. Dudík, Y. E. Chee, and C. J. Yates. 2011. "A statistical explanation of MaxEnt for ecologists." Diversity and Distributions 17 (1):43-57. doi: 10.1111/j.1472-4642.2010.00725.x.

Elmendorf, S. C., G. H. R. Henry, R. D. Hollister, R. G. Bjork, N. Boulanger-Lapointe, E. J. Cooper, J. H. C. Cornelissen, et al. 2012. "Plot-scale evidence of tundra vegetation change and links to recent summer warming." Nature Climate Change 2 (6):453-7. doi: 10.1038/nclimate1465.

Haralick, R. M., I. Dinstein, and K. Shanmugam. 1973. "Textural Features for Image Classification." IEEE Transactions on Systems, Man and Cybernetics SMC-3 (6):610-21. doi: 10.1109/TSMC.1973.4309314.

Hugelius, G., J. Routh, P. Kuhry, and P. Crill. 2012. "Mapping the degree of decomposition and thaw remobilization potential of soil organic matter in discontinuous permafrost terrain." Journal of Geophysical Research: Biogeosciences 117 (2). doi: 10.1029/2011JG001873.

Jorgenson, M. T., and G. Grosse. 2016. "Remote Sensing of Landscape Change in Permafrost Regions." Permafrost and Periglacial Processes 27 (4):324-38. doi: 10.1002/ppp.1914.

Juutinen, S., T. Virtanen, V. Kondratyev, T. Laurila, M. Linkosalmi, J. Mikola, J. Nyman, A. Räsänen, J-P. Tuovinen, and M. Aurela. 2017. "Spatial variation and seasonal dynamics of leaf-area index in the arctic tundra-implications for linking ground observations and satellite images." Environmental Research Letters 12:095002. doi: https://doi.org/10.1088/1748-9326/aa7f85.

Kavzoglu, T., and I. Colkesen. 2013. "An assessment of the effectiveness of a rotation forest ensemble for land-use and land-cover mapping." International journal of remote sensing 34 (12):4224-41. doi: 10.1080/01431161.2013.774099.

Kursa, M. B., and W. R. Rudnicki. 2010. "Feature Selection with the Boruta Package." Journal of Statistical Software 36 (11):1-13. 
Laidler, G. J., and P. Treitz. 2003. "Biophysical remote sensing of arctic environments." Progress in Physical Geography 27 (1):44-68. doi: 10.1191/0309133303pp358ra.

Li, J., M. Tran, and J. Siwabessy. 2016. "Selecting Optimal Random Forest Predictive Models: A Case Study on Predicting the Spatial Distribution of Seabed Hardness." Plos One 11 (2). doi: 10.1371/journal.pone.0149089.

Li, P., and H. Xu. 2010. "Land-cover change detection using one-class support vector machine." Photogrammetric Engineering and Remote Sensing 76 (3):255-63.

Li, W., Q. Guo, and C. Elkan. 2011. "A positive and unlabeled learning algorithm for one-class classification of remote-sensing data." Ieee Transactions on Geoscience and Remote Sensing 49 (2):717-25. doi: 10.1109/TGRS.2010.2058578.

Li, W. K., and Q. H. Guo. 2010. "A maximum entropy approach to one-class classification of remote sensing imagery." International journal of remote sensing 31 (8):2227-35. doi: 10.1080/01431161003702245.

Li, X. J., W. T. Chen, X. W. Cheng, and L. Z. Wang. 2016. "A Comparison of Machine Learning Algorithms for Mapping of Complex Surface-Mined and Agricultural Landscapes Using ZiYuan-3 Stereo Satellite Imagery." Remote Sensing 8 (6). doi: $10.3390 / \mathrm{rs} 8060514$.

Liaw, A., and M. Wiener. 2002. "Classification and Regression by randomForest." $R$ News 2 (3): 18-22

Lin, J., X. Liu, K. Li, and X. Li. 2014. "A maximum entropy method to extract urban land by combining MODIS reflectance, MODIS NDVI, and DMSP-OLS data." International journal of remote sensing 35 (18):6708-27. doi: 10.1080/01431161.2014.960623.

Liu, B., Y. Dai, X. Li, W. S. Lee, and P. S. Yu. 2003. Building Text Classifiers Using Positive and Unlabeled Examples. Paper presented at the Proceedings of the Third IEEE International Conference on Data Mining (ICDM '03).

Liu, R., W. Li, X. Liu, X. Lu, T. Li, and Q. Guo. 2018. "An Ensemble of Classifiers Based on Positive and Unlabeled Data in One-Class Remote Sensing Classification." Ieee Journal of Selected Topics in Applied Earth Observations and Remote Sensing 11 (2):572-84. doi: 10.1109/JSTARS.2017.2789213.

Low, F., U. Michel, S. Dech, and C. Conrad. 2013. "Impact of feature selection on the accuracy and spatial uncertainty of per-field crop classification using Support Vector Machines." ISPRS Journal of Photogrammetry and Remote Sensing 85:102-19. doi: 10.1016/j.isprsjprs.2013.08.007.

Mack, B., R. Roscher, S. Stenzel, H. Feilhauer, S. Schmidtlein, and B. Waske. 2016. "Mapping raised bogs with an iterative one-class classification approach." ISPRS Journal of Photogrammetry and Remote Sensing 120:53-64. doi: 10.1016/j.isprsjprs.2016.07.008.

Mack, B., R. Roscher, and B. Waske. 2014. "Can I Trust My One-Class Classification?" Remote Sensing 6 (9):8779-802. doi: 10.3390/rs6098779.

Mack, B., and B. Waske. 2017. "In-depth comparisons of MaxEnt, biased SVM and one-class SVM for one-class classification of remote sensing data." Remote Sensing Letters 8 (3):290-9. doi: 10.1080/2150704x.2016.1265689.

Marushchak, M. E., I. Kiepe, C. Biasi, V. Elsakov, T. Friborg, T. Johansson, H. Soegaard, T. Virtanen, and P. J. Martikainen. 2013. "Carbon dioxide balance of subarctic tundra from plot to regional scales." Biogeosciences 10 (1):437-52. doi: $10.5194 / \mathrm{bg}-10-437-2013$. 
Marushchak, M. E., A. Pitkämäki, H. Koponen, C. Biasi, M. Seppälä, and P. J. Martikainen. 2011. "Hot spots for nitrous oxide emissions found in different types of permafrost peatlands." Global Change Biology 17 (8):2601-14. doi: 10.1111/j.1365-2486.2011.02442.x.

McCarthy, M. J., and J. N. Halls. 2014. "Habitat mapping and change assessment of coastal environments: An examination of worldview-2, quickbird, and ikonos satellite imagery and airborne lidar for mapping barrier island habitats." ISPRS International Journal of Geo-Information 3 (1):297-325. doi: 10.3390/ijgi3010297.

McFeeters, S. K. 1996. "The use of the Normalized Difference Water Index (NDWI) in the delineation of open water features." International journal of remote sensing 17 (7):1425-32. doi: 10.1080/01431169608948714.

Mountrakis, G., J. Im, and C. Ogole. 2011. "Support vector machines in remote sensing: A review." ISPRS Journal of Photogrammetry and Remote Sensing 66 (3):24759. doi: 10.1016/j.isprsjprs.2010.11.001.

Myers-Smith, I. H., S. C. Elmendorf, P. S. A. Beck, M. Wilmking, M. Hallinger, D. Blok, K. D. Tape, et al. 2015. "Climate sensitivity of shrub growth across the tundra biome." Nature Climate Change 5 (9):887-+. doi: 10.1038/nclimate2697.

Novack, T., T. Esch, H. Kux, and U. Stilla. 2011. "Machine learning comparison between WorldView-2 and QuickBird-2-simulated imagery regarding objectbased urban land cover classification." Remote Sensing 3 (10):2263-82. doi: $10.3390 / \mathrm{rs} 3102263$.

Noviello, M., B. Cafarelli, C. Calculli, A. Sarris, and P. Mairota. 2018. "Investigating the distribution of archaeological sites: Multiparametric vs probability models and potentials for remote sensing data." Applied Geography 95:34-44. doi: 10.1016/j.apgeog.2018.04.005.

Obu, J., H. Lantuit, I. Myers-Smith, B. Heim, J. Wolter, and M. Fritz. 2017. "Effect of terrain characteristics on soil organic carbon and total nitrogen stocks in soils of Herschel Island, western Canadian Arctic." Permafrost and Periglacial Processes 28 (1):92-107. doi: 10.1002/ppp.1881.

Pacifici, F., M. Chini, and W. J. Emery. 2009. "A neural network approach using multiscale textural metrics from very high-resolution panchromatic imagery for urban land-use classification." Remote Sensing of Environment 113 (6):1276-92. doi: 10.1016/j.rse.2009.02.014.

Pau, G., F. Fuchs, O. Sklyar, M. Boutros, and W. Huber. 2010. "EBImage-an R package for image processing with applications to cellular phenotypes." Bioinformatics 26 (7):979-81. doi: 10.1093/bioinformatics/btq046.

Peterson, R. A., and W. B. Krantz. 2003. "A mechanism for differential frost heave and its implications for patterned-ground formation." Journal of Glaciology 49 (164):69-80. doi: 10.3189/172756503781830854.

Pflugmacher, D., O. N. Krankina, W. B. Cohen, M. A. Friedl, D. Sulla-Menashe, R. E. Kennedy, P. Nelson, et al. 2011. "Comparison and assessment of coarse resolution land cover maps for Northern Eurasia." Remote Sensing of Environment 115 (12):3539-53. doi: 10.1016/j.rse.2011.08.016.

Phillips, S. J., R. P. Anderson, and R. E. Schapire. 2006. "Maximum entropy modeling of species geographic distributions." Ecological Modelling 190 (3-4):231-59. doi: 10.1016/j.ecolmodel.2005.03.026.

Poona, N. K., A. van Niekerk, R. L. Nadel, and R. Ismail. 2016. "Random Forest (RF) Wrappers for Waveband Selection and Classification of Hyperspectral Data." Applied Spectroscopy 70 (2):322-33. doi: 10.1177/0003702815620545. 
R Core Team. 2015. "R: A language and environment for statistical computing." R Foundation for Statistical Computing. https://www.R-project.org/.

Rasanen, A., M. Kuitunen, E. Tomppo, and A. Lensu. 2014. "Coupling high-resolution satellite imagery with ALS-based canopy height model and digital elevation model in object-based boreal forest habitat type classification." ISPRS Journal of Photogrammetry and Remote Sensing 94:169-82. doi: 10.1016/j.isprsjprs.2014.05.003.

Repo, M. E., S. Susiluoto, S. E. Lind, S. Jokinen, V. Elsakov, C. Biasi, T. Virtanen, and P. J. Martikainen. 2009. "Large N2O emissions from cryoturbated peat soil in tundra." Nature Geoscience 2 (3):189-92. doi: 10.1038/ngeo434.

Rodriguez-Galiano, Victor Francisco, Bardan Ghimire, John Rogan, Mario ChicaOlmo, and Juan Pedro Rigol-Sanchez. 2012. "An assessment of the effectiveness of a random forest classifier for land-cover classification." ISPRS Journal of Photogrammetry and Remote Sensing 67:93-104.

Rodriguez, J. J., and L. I. Kuncheva. 2006. "Rotation forest: A new classifier ensemble method." Ieee Transactions on Pattern Analysis and Machine Intelligence 28 (10):1619-30. doi: 10.1109/tpami.2006.211.

Rouse, J. W. Jr., R. H. Haas, J. A. Schell, and D. W. Deering. 1973. "Monitoring vegetation systems in the Great Plains with ERTS." In Third Earth Resources Technology Satellite-1 Symposium, 309-17. Washington, DC: NASA.

Räsänen, Aleksi, Antti Rusanen, Markku Kuitunen, and Anssi Lensu. 2013. "What makes segmentation good? A case study in boreal forest habitat mapping." International journal of remote sensing 34 (23):8603-27.

Samsudin, S. H., H. Z. M. Shafri, A. Hamedianfar, and S. Mansor. 2015. "Spectral feature selection and classification of roofing materials using field spectroscopy data." Journal of Applied Remote Sensing 9. doi: 10.1117/1.jrs.9.095079.

Sanchez-Hernandez, C., D. S. Boyd, and G. M. Foody. 2007. "Mapping specific habitats from remotely sensed imagery: Support vector machine and support vector data description based classification of coastal saltmarsh habitats." Ecological Informatics 2 (2):83-8. doi: 10.1016/j.ecoinf.2007.04.003.

Sannel, A. B. K., and P. Kuhry. 2011. "Warming-induced destabilization of peat plateau/thermokarst lake complexes." Journal of Geophysical Research: Biogeosciences 116 (3). doi: 10.1029/2010JG001635.

Schölkopf, B., R. Williamson, A. Smola, J. Shawe-Taylor, and J. Piatt. 2000. Support vector method for novelty detection. Paper presented at the Advances in Neural Information Processing Systems.

Segal, R. A., T. C. Lantz, and S. V. Kokelj. 2016. "Acceleration of thaw slump activity in glaciated landscapes of the Western Canadian Arctic." Environmental Research Letters 11 (3). doi: 10.1088/1748-9326/11/3/034025.

Seppälä, M. 2003. "Surface abrasion of palsas by wind action in Finnish Lapland." Geomorphology 52 (1-2):141-8. doi: 10.1016/S0169-555X(02)00254-4.

Singh, Ashbindu. 1989. "Review article digital change detection techniques using remotely-sensed data." International journal of remote sensing 10 (6):9891003.

Song, B. Q., P. J. Li, J. Li, and A. Plaza. 2016. "One-Class Classification of Remote Sensing Images Using Kernel Sparse Representation." Ieee Journal of Selected Topics in Applied Earth Observations and Remote Sensing 9 (4):1613-23. doi: 10.1109/jstars.2015.2508285. 
Stenzel, S., F. E. Fassnacht, B. Mack, and S. Schmidtlein. 2017. "Identification of high nature value grassland with remote sensing and minimal field data." Ecological Indicators 74:28-38. doi: 10.1016/j.ecolind.2016.11.005.

Stenzel, S., H. Feilhauer, B. Mack, A. Metz, and S. Schmidtlein. 2014. "Remote sensing of scattered Natura 2000 habitats using a one-class classifier." International Journal of Applied Earth Observation and Geoinformation 33:211-7. doi: 10.1016/j.jag.2014.05.012.

Stow, D. A., A. Hope, D. McGuire, D. Verbyla, J. Gamon, F. Huemmrich, S. Houston, et al. 2004. "Remote sensing of vegetation and land-cover change in Arctic Tundra Ecosystems." Remote Sensing of Environment 89 (3):281-308. doi: 10.1016/j.rse.2003.10.018.

Tape, K., M. Sturm, and C. Racine. 2006. "The evidence for shrub expansion in Northern Alaska and the Pan-Arctic." Global Change Biology 12 (4):686-702. doi: 10.1111/j.1365-2486.2006.01128.x.

Tewkesbury, Andrew P, Alexis J Comber, Nicholas J Tate, Alistair Lamb, and Peter F Fisher. 2015. "A critical synthesis of remotely sensed optical image change detection techniques." Remote Sensing of Environment 160:1-14.

Wang, P., L. Mommer, J. van Ruijven, F. Berendse, T. C. Maximov, and Mmpd Heijmans. 2016. "Seasonal changes and vertical distribution of root standing biomass of graminoids and shrubs at a Siberian tundra site." Plant and Soil 407 (1-2):55-65. doi: 10.1007/s11104-016-2858-5.

Vapnik, V. 1982. Estimation of Dependences Based on Empirical Data. Vol. 40. New York: Springer-Verlag.

Vert, J.-P., K. Tsuda, and B. Schölkopf. 2004. "A primer on kernel methods." In Kernel Methods in Computational Biology, edited by B. Schölkopf, K. Tsuda and J.-P. Vert, 35-70. Cambridge, MA, USA: MIT Press.

Westermann, S., C. R. Duguay, G. Grosse, and A. Kääb. 2014. "Remote sensing of permafrost and frozen ground." In Remote Sensing of the Cryosphere, 307-44.

Virtanen, T., and M. Ek. 2014. "The fragmented nature of tundra landscape." International Journal of Applied Earth Observation and Geoinformation 27:412. doi: 10.1016/j.jag.2013.05.010.

Voigt, C., R. E. Lamprecht, M. E. Marushchak, S. E. Lind, A. Novakovskiy, M. Aurela, P. J. Martikainen, and C. Biasi. 2016. "Warming of subarctic tundra increases emissions of all three important greenhouse gases - carbon dioxide, methane, and nitrous oxide." Global Change Biology. doi: 10.1111/gcb.13563.

Väliranta, M., M. Marushchak, J.-P. Tuovinen, A. Lohila, C. Biasi, T. Ronkainen, H. Zhang, et al. 2018. "Increased climate forcing of high-latitude peatlands due to permafrost initiation." Submitted manuscript.

Xu, X., X. Liu, X. Li, Q. Xin, Y. Chen, Q. Shi, and B. Ai. 2016. "Global snow cover estimation with Microwave Brightness Temperature measurements and oneclass in situ observations." Remote Sensing of Environment 182:227-51. doi: 10.1016/j.rse.2016.05.010.

Yu, Q., H. Epstein, R. Engstrom, and D. Walker. 2017. "Circumpolar arctic tundra biomass and productivity dynamics in response to projected climate change and herbivory." Global Change Biology. doi: 10.1111/gcb.13632. 
850 Table 1. F-scores of the different classifiers using the parameter combinations yielding

851 highest $F$-score values. Values are calculated based on two different evaluations: (1)

852 out-of-bag (RF) or tenfold cross-validation (other classifiers) estimates using the

853 training data only, or (2) using independent test data. The highest $F$-scores for each

854 image and classification setting are marked in bold.

\begin{tabular}{|c|c|c|c|c|c|c|c|c|c|}
\hline \multirow{2}{*}{ Evaluation } & \multirow{2}{*}{ Classification } & \multicolumn{4}{|c|}{ Binary } & \multicolumn{4}{|c|}{ Positive and unlabelled } \\
\hline & & OCSVM & BSVM & RF & ROF & OCSVM & BSVM & $\mathrm{RF}$ & ROF \\
\hline \multirow{3}{*}{$\begin{array}{l}\text { Training data } \\
\text { cross-validation }\end{array}$} & QB & 0.85 & 0.89 & 0.88 & 0.94 & 0.90 & 0.93 & 0.94 & 0.96 \\
\hline & WV-3LR & 0.87 & 0.92 & 0.92 & 0.93 & 0.95 & 0.96 & 0.96 & 0.96 \\
\hline & WV-3HR & 0.77 & 0.86 & 0.86 & 0.91 & 0.88 & 0.90 & 0.90 & 0.95 \\
\hline \multirow{3}{*}{$\begin{array}{l}\text { Independent test } \\
\text { data }\end{array}$} & QB & 0.48 & 0.39 & 0.48 & 0.40 & 0.44 & 0.45 & 0.46 & 0.42 \\
\hline & WV-3LR & 0.32 & 0.31 & 0.38 & 0.22 & 0.42 & 0.45 & 0.42 & 0.34 \\
\hline & WV-3HR & 0.42 & 0.48 & 0.57 & 0.52 & 0.43 & 0.56 & 0.48 & 0.53 \\
\hline
\end{tabular}

855 Table 2. Classification accuracy results for the QB classifications. The best

856 performances for the binary and PU settings are marked in bold.

\begin{tabular}{|c|c|c|c|c|c|c|c|c|}
\hline \multirow{2}{*}{ Performance metric } & \multicolumn{4}{|c|}{ Binary } & \multicolumn{4}{|c|}{ PU } \\
\hline & OCSVM & BSVM & $\mathrm{RF}$ & $\mathrm{ROF}$ & OCSVM & BSVM & RF & $\mathrm{ROF}$ \\
\hline User's accuracy $(\%)$ & 36.9 & 46.7 & 43.7 & 39.2 & 34.8 & 42.0 & 46.8 & 58.9 \\
\hline Segment that is $50 \%$ correct $(\%)$ & 41.7 & 63.2 & 54.7 & 57.4 & 39.2 & 54.5 & 63.0 & 84.6 \\
\hline Segment that is $10 \%$ correct $(\%)$ & 80.6 & 92.1 & 88.7 & 68.1 & 74.7 & 81.8 & 91.3 & 100.0 \\
\hline Producer's accuracy $(\%)$ & 60.0 & 42.4 & 53.7 & 43.4 & 59.8 & 21.5 & 50.0 & 34.4 \\
\hline Reference area that is $50 \%$ mapped $(\%)$ & 56.2 & 37.1 & 49.4 & 31.5 & 56.2 & 18.0 & 42.7 & 25.8 \\
\hline Reference area that is $10 \%$ mapped $(\%)$ & 65.2 & 40.4 & 52.8 & 34.8 & 65.2 & 19.1 & 46.1 & 29.2 \\
\hline Number of segment classified as bare peat & 72 & 38 & 53 & 47 & 79 & 22 & 46 & 26 \\
\hline Number of bare peat area in the reference & 89 & 89 & 89 & 89 & 89 & 89 & 89 & 89 \\
\hline Mapped area (ha) & 0.866 & 0.472 & 0.643 & 0.580 & 0.914 & 0.267 & 0.558 & 0.308 \\
\hline Bare peat area in the reference (ha) & 0.521 & 0.521 & 0.521 & 0.521 & 0.521 & 0.521 & 0.521 & 0.521 \\
\hline Number of segment total & 636 & 455 & 418 & 437 & 741 & 291 & 436 & 290 \\
\hline Total (ha) & 9.102 & 6.686 & 5.939 & 6.231 & 10.030 & 4.364 & 6.070 & 4.311 \\
\hline
\end{tabular}


859 Table 3. Classification accuracy results for the WV-3LR classifications. The best

860 performances for the binary and PU settings are marked in bold.

\begin{tabular}{lccccccccc}
\hline \multirow{2}{*}{ Performance metric } & \multicolumn{4}{c}{ Binary } & & \multicolumn{4}{c}{ PU } \\
\cline { 2 - 5 } \cline { 8 - 10 } & OCSVM & BSVM & RF & ROF & & OCSVM & BSVM & RF & ROF \\
\hline User's accuracy (\%) & 31.7 & 25.7 & $\mathbf{5 4 . 2}$ & 21.8 & & 43.0 & 45.1 & $\mathbf{4 5 . 8}$ & 45.0 \\
Segment that is 50\% correct (\%) & 34.9 & 46.8 & $\mathbf{5 8 . 6}$ & 33.3 & & 44.7 & 48.1 & $\mathbf{4 8 . 9}$ & 53.1 \\
Segment that is 10\% correct (\%) & 72.1 & 72.3 & $\mathbf{8 2 . 8}$ & 52.4 & & $\mathbf{8 3 . 0}$ & 78.8 & 77.8 & 78.1 \\
Producer's accuracy (\%) & 31.3 & $\mathbf{3 7 . 7}$ & 28.9 & 22.6 & & 40.7 & $\mathbf{4 5 . 1}$ & 38.6 & 27.7 \\
Reference area that is 50\% mapped (\%) & 30.3 & $\mathbf{3 3 . 7}$ & 22.5 & 20.2 & & 37.1 & $\mathbf{3 9 . 3}$ & 33.7 & 23.6 \\
Reference area that is 10\% mapped (\%) & 36.0 & $\mathbf{3 8 . 2}$ & 25.8 & 22.5 & & 41.6 & $\mathbf{4 4 . 9}$ & 38.2 & 27.0 \\
Number of segment classified as bare peat & 43 & $\mathbf{4 7}$ & 29 & 42 & & 47 & $\mathbf{5 2}$ & 45 & 32 \\
Number of bare peat area in the reference & 89 & 89 & 89 & 89 & & 89 & 89 & 89 & 89 \\
Mapped area (ha) & $\mathbf{0 . 5 2 0}$ & 0.772 & 0.279 & 0.544 & & 0.503 & $\mathbf{0 . 5 2 6}$ & 0.443 & 0.323 \\
Bare peat area in the reference (ha) & 0.521 & 0.521 & 0.521 & 0.521 & & 0.521 & 0.521 & 0.521 & 0.521 \\
Number of segment total & 339 & 390 & 288 & 424 & & 365 & 395 & 368 & 314 \\
Total (ha) & 4.674 & 7.942 & 4.069 & 5.905 & & 4.746 & 5.469 & 5.369 & 4.306 \\
\hline
\end{tabular}

861

862 
863 Table 4. Classification accuracy results for the WV-3HR classifications. The best

864 performances for the binary and PU settings are marked in bold.

\begin{tabular}{|c|c|c|c|c|c|c|c|c|}
\hline \multirow{2}{*}{ Performance metric } & \multicolumn{4}{|c|}{ Binary } & \multicolumn{4}{|c|}{$\mathrm{PU}$} \\
\hline & OCSVM & BSVM & $\mathrm{RF}$ & ROF & OCSVM & BSVM & $\mathrm{RF}$ & ROF \\
\hline User's accuracy (\%) & 42.9 & 63.6 & 56.8 & 58.2 & 33.7 & 55.4 & 47.2 & 49.1 \\
\hline Segment that is $50 \%$ correct $(\%)$ & 50.7 & 76.5 & 66.3 & 69.6 & 40.2 & 65.8 & 54.1 & 61.4 \\
\hline Segment that is $10 \%$ correct $(\%)$ & 80.0 & 88.2 & 89.5 & 84.1 & 68.2 & 92.4 & 83.5 & 86.4 \\
\hline Producer’s accuracy (\%) & 40.6 & 38.4 & 57.4 & 47.3 & 59.9 & 55.7 & 49.2 & 56.8 \\
\hline Reference area that is $50 \%$ mapped (\%) & 43.8 & 32.6 & 56.2 & 41.6 & 65.2 & 53.9 & 53.9 & 58.4 \\
\hline Reference area that is $10 \%$ mapped (\%) & 55.1 & 46.1 & 68.5 & 52.8 & 79.8 & 62.9 & 67.4 & 66.3 \\
\hline Number of segment classified a & 75 & 51 & 86 & 69 & 132 & 80 & 85 & 88 \\
\hline Number of bare peat area in the reference & 89 & 89 & 89 & 89 & 89 & 89 & 89 & 89 \\
\hline Mapped area (ha) & 0.498 & 0.318 & 0.531 & 0.427 & 0.930 & 0.528 & 0.550 & 0.606 \\
\hline Bare peat area in the reference (ha) & 0.521 & 0.521 & 0.521 & 0.521 & 0.521 & 0.521 & 0.521 & 0.521 \\
\hline Number of segment total & 513 & 319 & 454 & 359 & 951 & 604 & 685 & 549 \\
\hline Total (ha) & 4.661 & 5.802 & 4.487 & 4.634 & 7.780 & 5.045 & 5.478 & 4.644 \\
\hline
\end{tabular}

865

866 
867 Table 5. Change detection metrics based on the QB and WV-3LR classifications.

\begin{tabular}{|c|c|c|c|c|c|c|}
\hline & \multicolumn{2}{|c|}{ QB } & \multicolumn{2}{|c|}{ WV-3LR } & \multicolumn{2}{|c|}{ Decrease $(\%)$} \\
\hline Metric & $\begin{array}{l}\text { Area } \\
\text { (ha) }\end{array}$ & $\begin{array}{c}\text { Number of } \\
\text { patches }\end{array}$ & $\begin{array}{l}\text { Area } \\
\text { (ha) }\end{array}$ & $\begin{array}{c}\text { Number of } \\
\text { patches }\end{array}$ & $\begin{array}{c}\text { Are } \\
\mathrm{a}\end{array}$ & $\begin{array}{l}\text { Number } \\
\text { of patches }\end{array}$ \\
\hline $\begin{array}{l}\text { Consensus of } 7 \\
\text { classifiers }\end{array}$ & 4.3 & 286 & 3.1 & 236 & 27.9 & 17.5 \\
\hline $\begin{array}{l}\text { Consensus of } 5 \\
\text { classifiers }\end{array}$ & 5.7 & 401 & 4.4 & 318 & 22.8 & 20.7 \\
\hline $\begin{array}{l}\text { Consensus of } 3 \\
\text { classifiers }\end{array}$ & 8.4 & 616 & 5.2 & 375 & 38.1 & 39.1 \\
\hline Lowest estimate & 4.3 & 290 & 4.1 & 288 & 4.7 & 0.7 \\
\hline Average & 7.0 & 487 & 5.3 & 360 & 24.3 & 26.1 \\
\hline Highest estimate & 10.0 & 741 & 7.9 & 424 & 21.0 & 42.8 \\
\hline
\end{tabular}

$62^{\circ} 53^{\prime} 00^{\prime \prime E} 62^{\circ} 54^{\prime} 00^{\prime \prime E ~} 62^{\circ} 55^{\prime} 00^{\prime \prime E} 62^{\circ} 56^{\prime} 00^{\prime \prime E ~} 62^{\circ} 57^{\prime} 00^{\prime \prime E}$

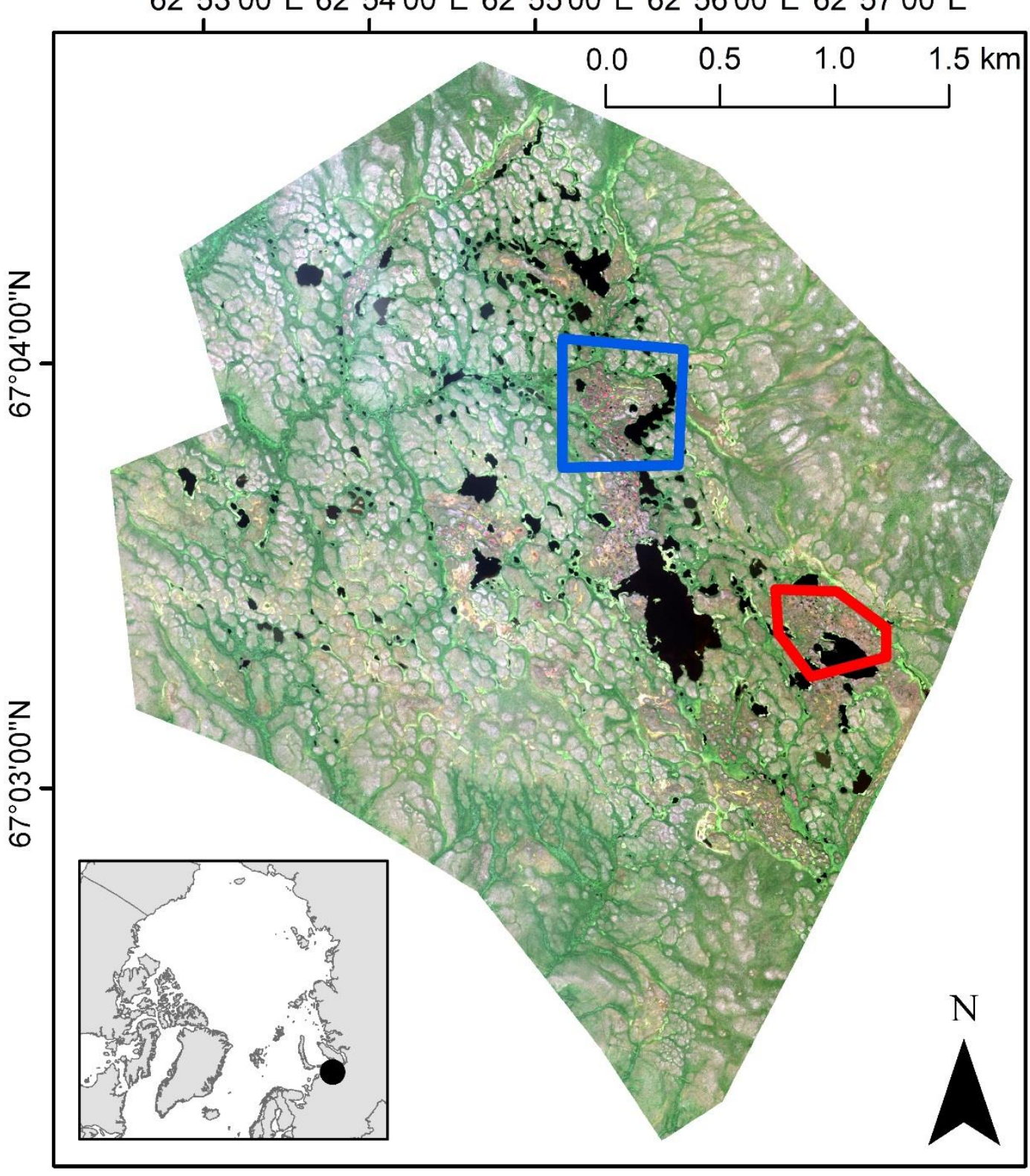

870 and the test area in red. Image: WorldView-3 @DigitalGlobe. 


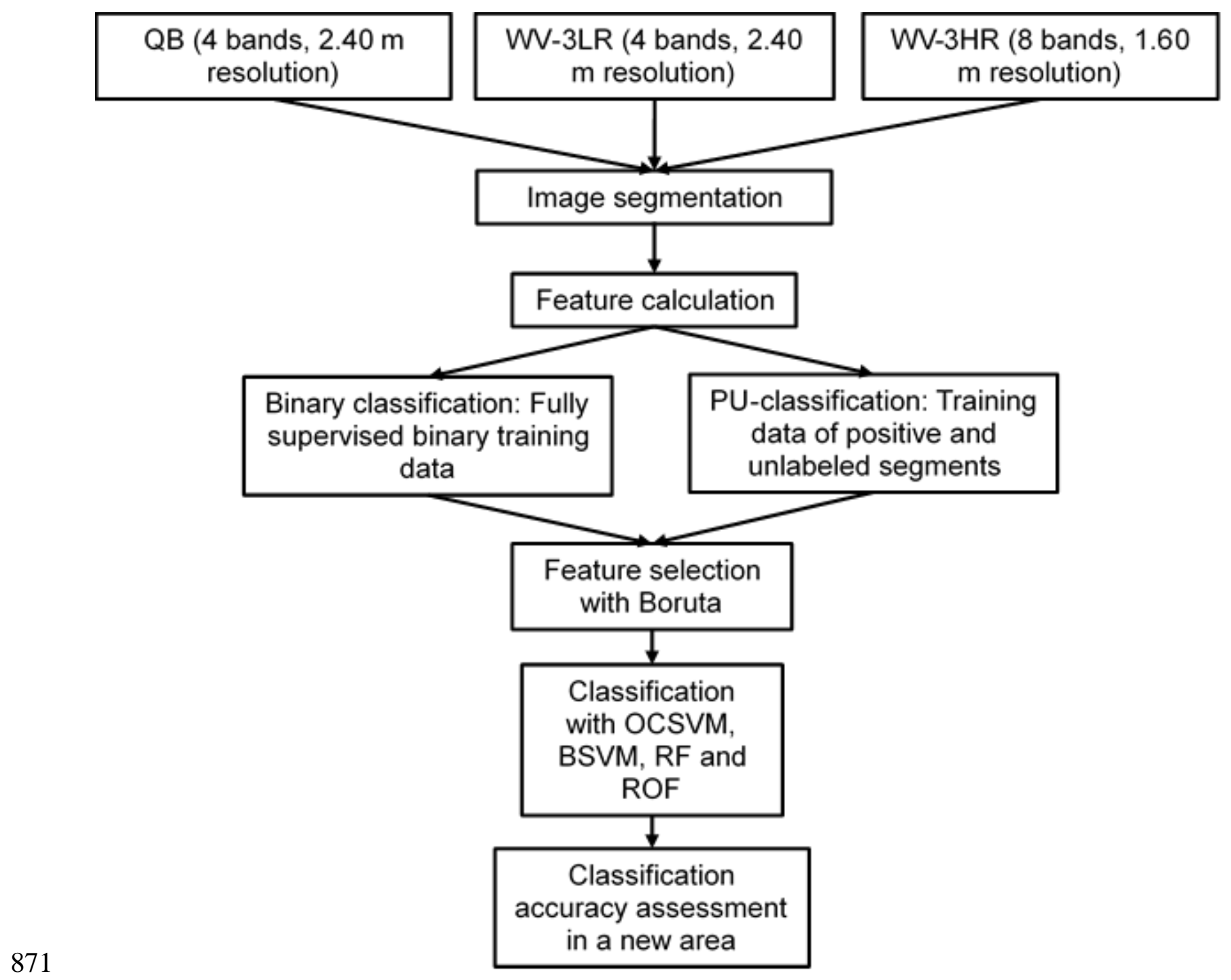

872 Figure 2. The workflow of the methods used. 


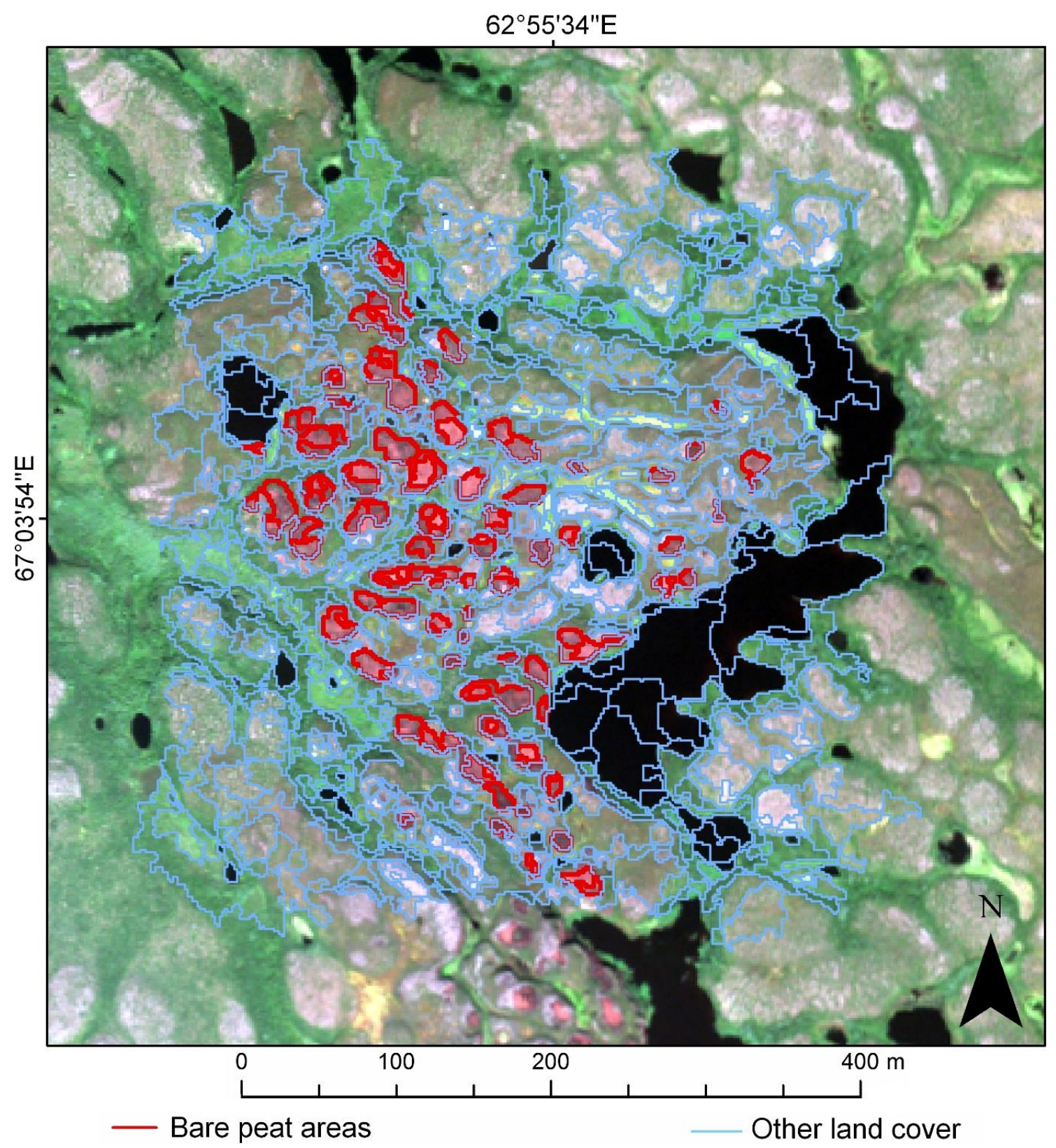

874 Figure 3. The training area for the WV-3HR classifications. Bare peat areas were used

875 both in binary and positive and unlabelled settings and other land cover types in the 876 binary setting. Image CDigitalGlobe. 


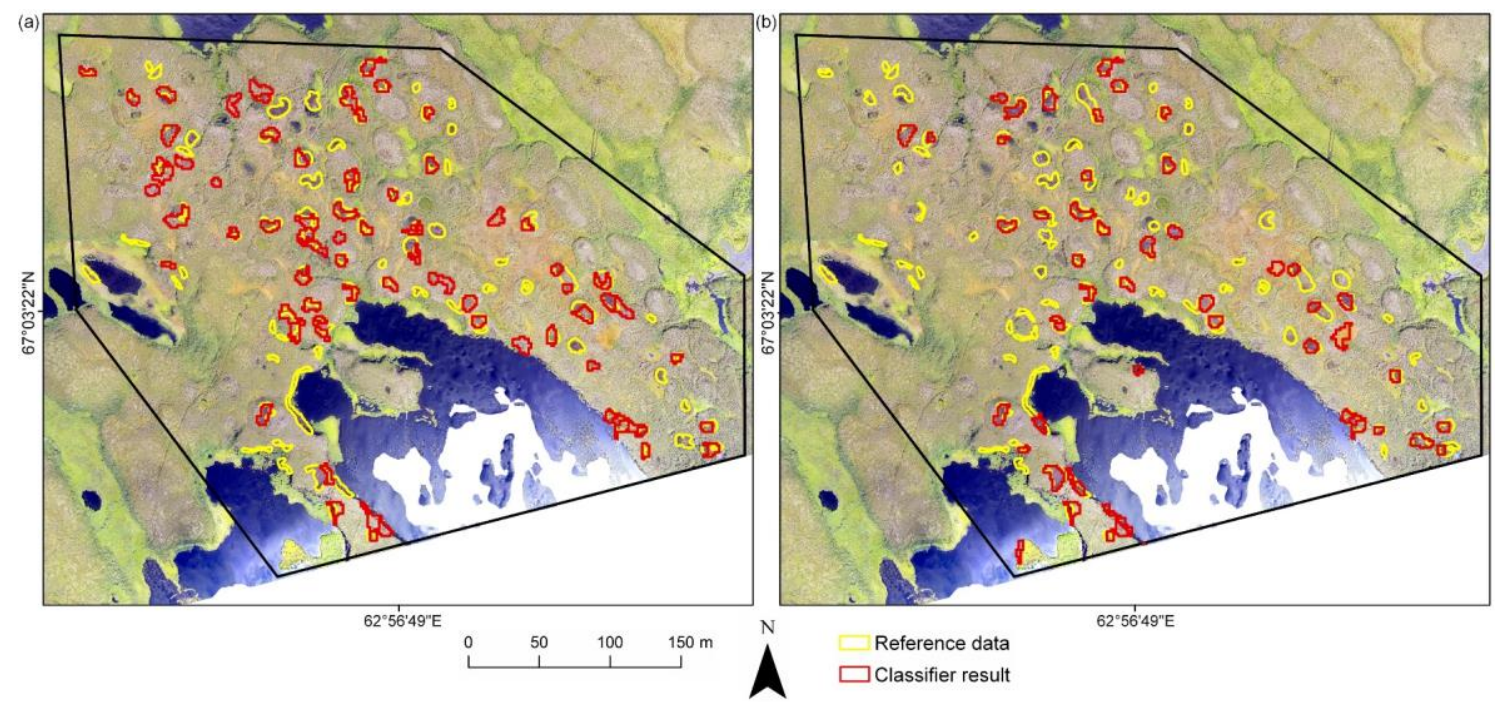

877
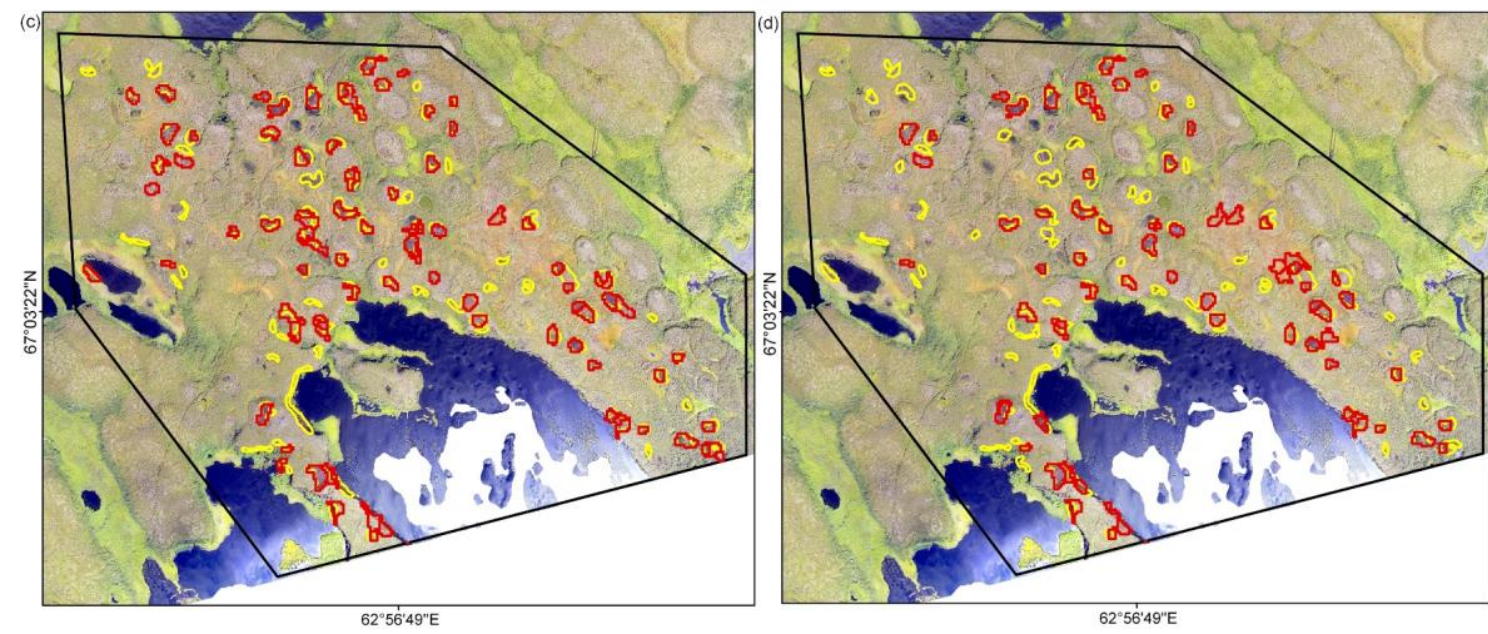

878 Figure 4. Visualizations of the OCSVM (a), BSVM (b), RF (c), and ROF (d)

879 classifications for the WV-3HR classifications using the binary setting. Background

880 image: drone image from the validation area. 